Zoo Biology 17:525-534 (1998)

\title{
Public Perceptions of Behavioral Enrichment: Assumptions Gone Awry
}

\author{
M.E. McPhee, ${ }^{1 *}$ J.S. Foster, ${ }^{2}$ M. Sevenich, ${ }^{3}$ and C.D. Saunders ${ }^{4}$ \\ ${ }^{1}$ University of Michigan, Ann Arbor, Michigan \\ ${ }^{2}$ Seneca Zoo Society, Rochester, New York \\ ${ }^{3}$ Disney's Animal Kingdom, Lake Buena Vista, Florida \\ ${ }^{4}$ Brookfield Zoo, Brookfield, Illinois
}

\begin{abstract}
More and more, zoos are integrating behavioral enrichment programs into their management routines. Given the newness of such programs on an official level, however, there are an increasing number of enrichment decisions based on assumption. Enrichment is typically not provided on exhibit, especially for exhibits considered to be more naturalistic, because it is assumed to affect visitors' experience negatively. To test that assumption, visitors were interviewed in front of four exhibits - an outdoor barren grotto, an outdoor vegetated grotto, an indoor immersion exhibit, and an outdoor traditional cage - each with either natural, nonnatural or no enrichment objects present. Specifically, we wanted to know whether 1) the exhibit's perceived educational message, 2) the animal's perceived "happiness," and 3) the visitor perceptions of enrichment, the naturalism of animal's behavior, and zoo animal well-being changed as a function of object type. Overall, the type of enrichment object had little impact on visitor perceptions. In the outdoor barren grotto, only visitor perceptions of exhibit naturalism were affected by object type. In the outdoor vegetated grotto, object type influenced visitors perceptions of enrichment and exhibit naturalism. For the indoor immersion exhibit, general perceptions of enrichment and the perceived naturalism of the animal's behavior were affected. Finally, in the outdoor traditional cage, perceived educational message and general perceptions of enrichment changed as a function of object type. Zoo Biol 17:525-534, 1998. ๑) 1998 Wiley-Liss, Inc.
\end{abstract}

Key words: zoo; exhibit; naturalism; education

\section{INTRODUCTION}

Today, many zoos are including behavioral enrichment programs in their management practices. These programs are designed to increase animal visibility, de-

*Correspondence to: M.E. McPhee, Editor, Endangered Species UPDATE, University of Michigan, 430 E. University, Dana Building, Ann Arbor, MI 48109. E-mail: mmcphee@ umich.edu

Received for publication March 23, 1998; revision accepted October 14, 1998.

(C) 1998 Wiley-Liss, Inc. 
crease aberrant behaviors, and stimulate natural behaviors in a natural pattern. Enrichment items take a variety of forms, such as plastic Boomer balls ${ }^{\circledR}$, scents, or hollowed-out logs filled with treats. Unfortunately, not all items produce desired results with all animals, so zoo staff are constantly searching for new, creative, and more effective enrichment ideas [McKenzie et al., 1986; Shepherdson et al., 1998; Tripp, 1985; for further examples, see articles in The Shape of Enrichment, V. Hare ed]. In response, significant research and literature on enrichment initiatives have been generated [Carlstead et al., 1991; Markowitz, 1995; Newberry, 1995].

Little has been done, however, to address visitors' reactions to enrichment. As zoos shift from older, traditional enclosures to naturalistic "habitats," enrichment decisions are increasingly based not only on animal-related issues, but also on visitor experience. A general, but untested, assumption is that the use of non-natural enrichment devices in naturalistic exhibits negatively affects visitor experience by decreasing an exhibit's naturalism and weakening its educational message [Hutchins et al., 1979; Hancocks, 1980; Foster and Freeman, 1978 as cited in Forthman-Quick, 1984; Shepherdson, 1989]. For example, few zoo professionals consider the effect of a red ball on the perceived naturalism of a barred cage, but many worry about that same red ball in a multi-million dollar simulation of the Asian rainforest. These assumptions often prevent the use of enrichment items on exhibit, especially in those exhibits considered to be more naturalistic.

As zoos place more and more emphasis on enrichment programs, questions arise. What is the public's general perception of enrichment? How does enrichment affect either the exhibit's perceived naturalism or educational message?

To answer these questions at Brookfield Zoo, we created a study to measure visitors' opinions of and reactions to enrichment. Our goal was to understand better public perception of the behavioral enrichment techniques used and to develop guidelines to assist enrichment decisions. In this article, we outline our specific research questions, describe our experimental design, discuss the survey, and detail the results. Finally, we summarize the results and provide a brief conclusion.

\section{METHODS}

\section{Questions and Experimental Design}

To understand public perceptions of, and reactions to, enrichment, we asked, "Do the following change as a function of enrichment object type:

1. an exhibit's perceived educational message,

2. an animal's perceived "happiness,"

3. perceptions of enrichment,

4. perceived naturalism of animal's behavior,

5. perceptions of zoo animal well-being?"

(Note: These factors will be referred to as "animal happiness," "exhibit naturalism," etc. That these are visitor perceptions will be implied.) We developed a study using four exhibit types and three enrichment conditions. The exhibits were:

1. a barren, outdoor polar bear (Ursus arctos maritimus) grotto,

2. a vegetated, outdoor tiger (Panthera tigris altaica) grotto,

3. a traditional, barred, outdoor lynx (Lynx canadensis) cage,

4. an indoor immersion fishing cat (Prionailurus viverrina) exhibit. 
These exhibits were chosen for their diversity of environment, diversity of animal "charisma," consistency of animal type (they are all carnivores), and availability of various safe enrichment items.

In all exhibits, we considered the presence of natural and non-natural items, and in the traditional and barren enclosures we also considered the absence of items. Three objects were used for each condition. For natural items, we used woodwool, browse, and $\operatorname{logs}$ in the barren and traditional enclosures, but due to existing cage furniture, rocks, water, and $\log s$ were used in the immersion and vegetated exhibits. For non-natural items, a red Kong toy was used for smaller animals and a blue plastic barrel for larger animals. All animals in the non-natural treatment received a beige spoolie and red Boomer ball ${ }^{\circledR}$ of appropriate size. To elicit a stronger reaction, we specifically chose non-natural items that were colorful and conspicuous.

\section{Survey}

To collect data, we interviewed 829 randomly chosen visitors across the various conditions. Every other visitor who entered a predetermined space was approached and each interview, conducted by the same two interviewers, took approximately 10 min. First, a visitor was asked questions about his or her perceptions of the exhibit's naturalism (8-point scale). Second, the interviewer pointed out the enrichment items and the visitor was asked to assess the items' effect on exhibit naturalism. We asked 10 4point questions focusing on the aesthetic, functional, and general qualities of the items. Next, the visitor rated the items on a scale of 1-4 for 10 statements (40-point scale). Then we asked what the animal was doing, if the behavior was natural (4- point scale), and, again, the objects' effect on the behavior's naturalism. We then asked visitors if the animal was "happy" and if the exhibit taught more about the animal or the animal and its habitat. Finally, we explored perceptions of zoo animal well-being (i.e., attitudes toward captivity) (28-point scale), and pet-related attitudes (56-point scale) [Kafer et al., 1992]. There are two important notes: 1) the word happiness was chosen because visitors could easily relate to its meaning, and 2) to avoid influencing responses, the terms natural and non-natural were never defined for the visitor.

For all questions, responses were based either on a dichotomous scale (e.g., yes or no) or a 4-point scale (e.g., strongly agree, agree, disagree, or strongly disagree). For scale development, we pilot tested a number of statements that were generated by animal staff and communications specialists. To check for content and internal validity, the scores for individual statements were then correlated. To ensure the statements used in the final survey were yielding different, yet related, pieces of information, we excluded statements that were not significantly correlated and those that were too highly correlated with each other.

\section{Statistical Analysis}

To analyze the data, we used $\chi^{2}$ tests, one-way analysis of variance (ANOVA I), and two-way ANOVA (ANOVA II) with an a priori alpha of 0.05. We tested all data for assumptions of normality and equal variances. If they were not met, we either used an ANOVA on square root transformed data (t-ANOVA) or the KruskalWallis test (KW) [Neter et al., 1996]. 


\section{RESULTS}

The results of this study are rich and complex. They are presented here by question and are summarized in Table 1.

\section{Does the Exhibit's Perceived Educational Message Change as a Function of Object Type?}

We found that enrichment only affected the educational message in one of the four exhibits (outdoor traditional cage $\left(\chi^{2}, P<0.001\right)$ (Fig. 1). In the traditional enclosure with natural items, $63 \%$ of visitors felt the exhibit taught about the animal and its habitat, whereas $29 \%$ felt it taught about the animal only, and $9 \%$ felt it taught about neither. In the same exhibit with either nonnatural items or no items present, visitors learned more about the animal only (61 and 62\%, respectively). A few respondents said the exhibit didn't teach about either the animal or the habitat.

\section{Does the Animal's Perceived "Happiness" Change as a Function of Object Type?}

In none of the exhibits did enrichment affect perceptions of animal happiness (barren grotto, $\chi^{2}, P=0.341$; vegetated grotto, $\chi^{2}, P=0.177$; immersion exhibit, $\chi^{2}$, $P=0.489$; traditional cage, $\chi^{2}, P=0.449$ ). Eighty-two percent of visitors in front of the immersion exhibit felt the animal was "happy," versus $77 \%$ of visitors in front of the outdoor vegetated grotto, $64 \%$ at the outdoor barren grotto, and $49 \%$ at the traditional enclosure.

\section{Do Perceptions of Enrichment Change as a Function of Object Type?}

Visitors' perceptions of enrichment were affected by object type in all exhibits except the outdoor barren grotto (ANOVA I, $P=0.678$ ). In the outdoor vegetated grotto (ANOVA I, $P<0.001$ ), the immersion exhibit (ANOVA I, $P<0.001$ ), and traditional cage (KW, $P<0.001$ ), enrichment received a higher (i.e., more positive) score if the visitors were viewing natural items than if they were viewing non-natural items.

\section{Does the Exhibit's Perceived Naturalism Change as a Function of Object Type?}

Perceptions of exhibit naturalism were determined by two 4-point questions. The first asked whether the exhibit was similar to where this animal is found in the wild, and the second wanted to know, compared to where this animal is found in the wild, how visitors would rate the exhibit (very natural to very non-natural). These two scores were combined for an overall "naturalism score." We received some interesting responses to this question; for example, one respondent thought the Siberian tiger exhibit was not natural because it looked nothing like Africa. We found that object type did not affect exhibit naturalism in either the immersion (t-ANOVA, $P=0.069$ ) nor traditional exhibits (ANOVA I, $P=0.560$ ). Object type did, however, affect perceived naturalism in the barren (ANOVA I, $P=0.047$ ) and vegetated grottos (ANOVA I, $P=0.002$ ) (Fig. 2).

In the barren grotto, naturalism did not change between natural objects and no objects, but the presence of non-natural objects decreased the exhibit's perceived naturalism. Interestingly, in the vegetated grotto, the exhibit with non-natural objects received higher naturalism scores than an exhibit with natural objects. 
TABLE 1. The relationship between visitor perceptions and object type in different types of exhibits

\begin{tabular}{|c|c|c|c|c|c|c|}
\hline Exhibit & $\begin{array}{l}\text { Educational } \\
\text { message }\end{array}$ & $\begin{array}{c}\text { Animal } \\
\text { "happiness" }\end{array}$ & $\begin{array}{l}\text { Perceptions } \\
\text { of } \\
\text { enrichment }\end{array}$ & $\begin{array}{c}\text { Exhibit } \\
\text { naturalism }\end{array}$ & $\begin{array}{c}\text { Naturalism } \\
\text { of animal's } \\
\text { behavior }\end{array}$ & $\begin{array}{l}\text { Zoo animal } \\
\text { well-being }\end{array}$ \\
\hline $\begin{array}{l}\text { Barren } \\
\text { outdoor } \\
\text { grotto }\end{array}$ & No effect & No effect & No effect & $\begin{array}{l}\text { Non-natural } \\
\text { items } \\
\text { decreased } \\
\text { perceived } \\
\text { naturalism }\end{array}$ & No effect & No effect \\
\hline $\begin{array}{l}\text { Vegetated } \\
\text { outdoor } \\
\text { grotto }\end{array}$ & No effect & No effect & $\begin{array}{l}\text { Natural } \\
\quad \text { items } \\
\text { received } \\
\text { a more } \\
\text { positive } \\
\text { score }\end{array}$ & $\begin{array}{l}\text { Non-natural } \\
\text { items } \\
\text { increased } \\
\text { perceived } \\
\text { naturalism }\end{array}$ & No effect & No effect \\
\hline $\begin{array}{l}\text { Traditional } \\
\text { barred } \\
\text { outdoor } \\
\text { cage }\end{array}$ & $\begin{array}{l}\text { Natural } \\
\text { items } \\
\text { taught } \\
\text { more about } \\
\text { the animal } \\
\text { and its } \\
\text { habitat }\end{array}$ & No effect & $\begin{array}{l}\text { Natural } \\
\quad \text { items } \\
\text { received } \\
\text { a more } \\
\text { positive } \\
\text { score }\end{array}$ & No effect & No effect & No effect \\
\hline $\begin{array}{l}\text { Indoor } \\
\text { immersion } \\
\text { exhibit }\end{array}$ & No effect & No effect & $\begin{array}{l}\text { Natural } \\
\quad \text { items } \\
\text { received } \\
\text { a more } \\
\text { positive } \\
\text { score }\end{array}$ & No effect & $\begin{array}{l}\text { Non-natural } \\
\text { items } \\
\text { increased } \\
\text { perceived } \\
\text { naturalism }\end{array}$ & No effect \\
\hline
\end{tabular}

Although zoo animal well-being was influenced by a interaction between pet ownership and enrichment, zoo managers cannot control whether their visitors own pets, so it is considered a variable without significant impact. 


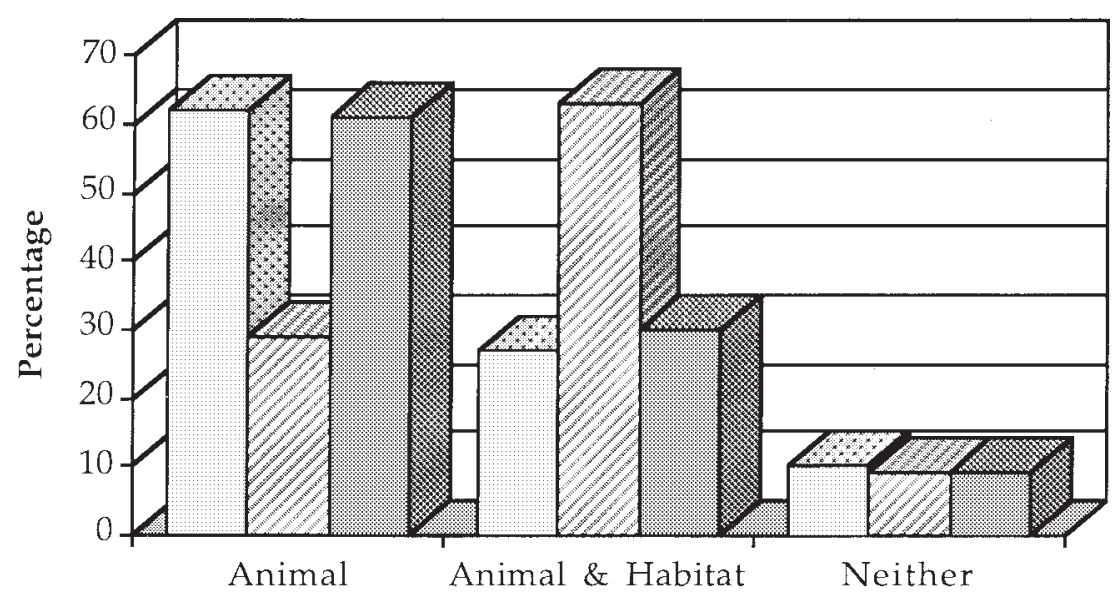

\section{$\square$ None $\square$ Natural $\square$ Non-natural}

Fig. 1. Change in perceived educational message as a function of object type in the outdoor traditional cage.

\section{Does the Perceived Naturalism of the Animal's Behavior Change as a Function of Object Type?}

Object type did not affect the naturalism of animal's behavior in either the barren grotto (t-ANOVA, $P=0.680)$, the vegetated grotto $(\mathrm{KW}, P=0.849)$, or the

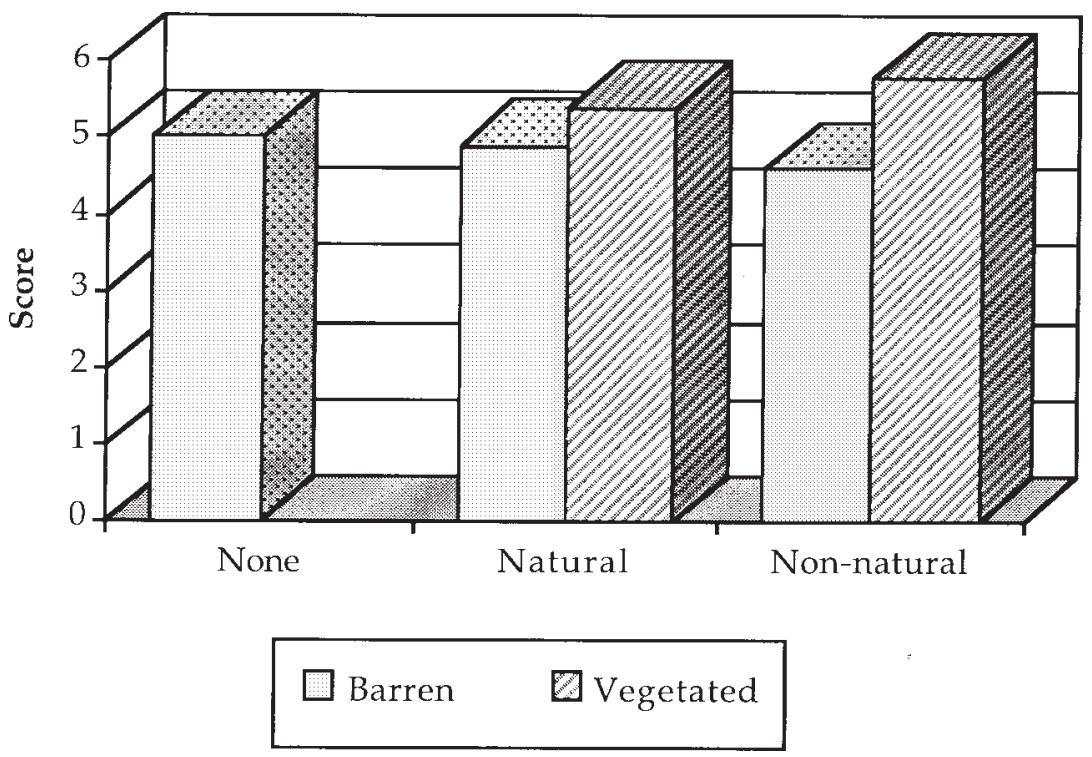

Fig. 2. Change in the exhibit's perceived naturalism as a function of object type. 
traditional cage (KW, $P=0.245)$. Object type did, however, affect the perceived naturalism of behavior in an immersion exhibit (KW, $P=0.005)$. Surprisingly, the behavior of an animal with non-natural objects is more natural than is the behavior with natural objects.

\section{Do Perceptions of Zoo Animal Well-being Change as a Function of Object Type?}

In none of the exhibits did perceptions of zoo animal well-being change as a function of object type (barren grotto, ANOVA I, $P=0.144$; vegetated grotto, ANOVA I, $P=0.943$; immersion exhibit, ANOVA I, $P=0.096$; traditional cage, ANOVA I, $P$ $=0.506$ ). The average score for the four exhibits was 20 of 28 , which indicates that visitors generally have positive perceptions of zoo animal well-being.

In the immersion exhibit and traditional cage, however, there was an interaction between object type and whether the respondent owned a pet. For the indoor immersion exhibit (ANOVA II, $P=0.032$ ), pet owners had the most positive perceptions of well-being in front of an exhibit with natural objects, whereas non-pet owners had the most positive perceptions when in front of an exhibit with non-natural objects (Fig. 3). In the traditional cage (ANOVA II, $P=0.003$ ), pet owners had the most positive perceptions of well-being in front of an exhibit with either natural or non-natural objects. Conversely, non-pet owners had the most positive perceptions when in front of an exhibit with no objects (Fig. 4). For the barren grotto (ANOVA II, $P=0.068$ ), the interaction is not significant. It is close enough, however, that it is an interesting case. Like the traditional cage, pet owners had the most positive perceptions of well-being in front of an exhibit with either natural or non-natural objects. Conversely, non-pet owners had the most positive perceptions when in front of an exhibit with no objects.

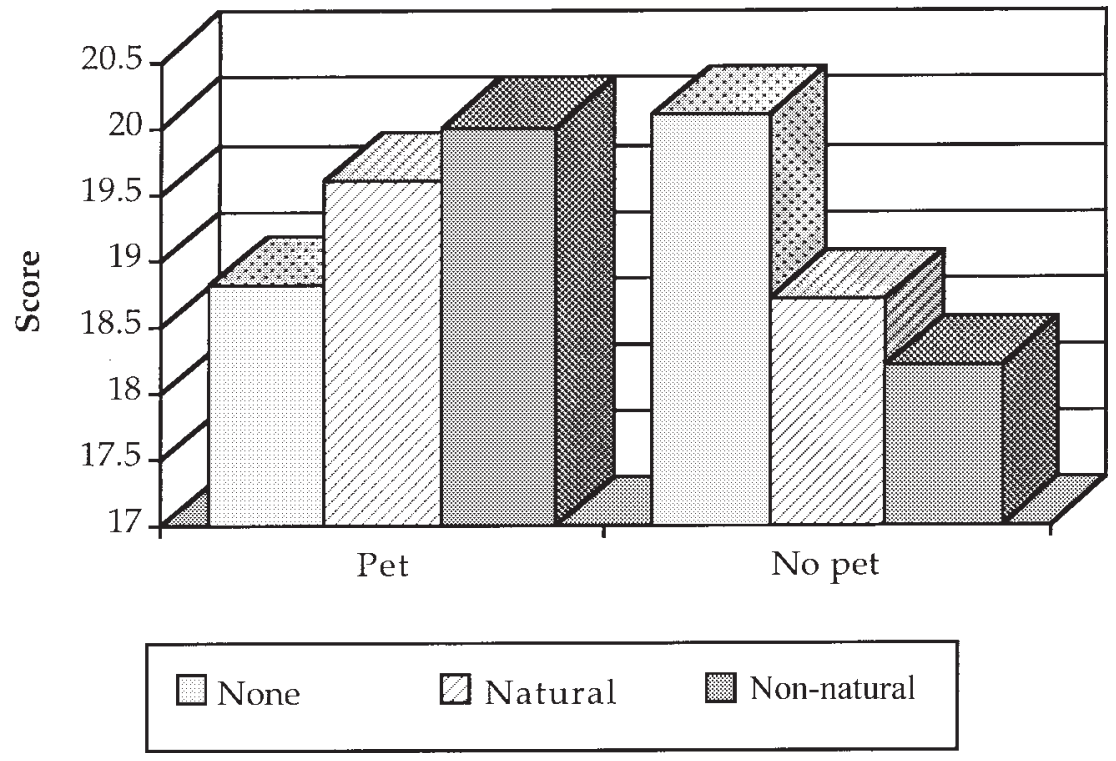

Fig. 3. Effects of pet ownership on perceptions of zoo animal well-being for the indoor immersion exhibit. 


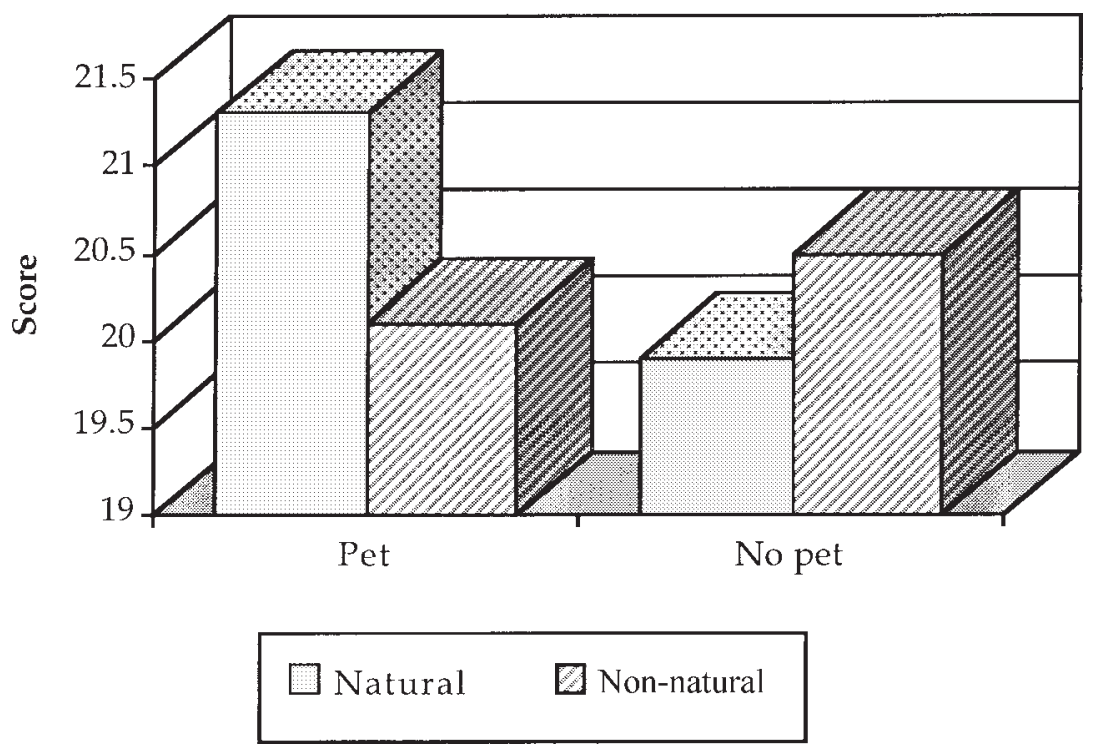

Fig. 4. Effects of pet ownership on perceptions of zoo animal well-being for the outdoor traditional cage.

\section{DISCUSSION}

The impacts of behavioral enrichment on both animal and visitor have entered the forefront of captive animal research and protocol. Many decisions, however, are still based on the assumption that non-natural enrichment negatively affects visitors' experiences. Enrichment decisions often focus less on animal needs and more on visitor needs. According to these data, however, there is room to shift. In the majority of cases, the presence of enrichment, regardless of type, did not influence visitors' perceptions (Table 1). Visitors generally recognize the purpose of enrichment and understand its importance-they are more receptive to red Boomer balls ${ }^{\circledR}$ and blue barrels than believed.

First, the exhibit's perceived educational message was only affected by object type in the traditional barred cage. The traditional cage with natural objects elicited responses such as "[I learn more about the animal and its habitat because the objects] give the feel of the natural habitat," whereas the majority of respondents in front of a traditional cage with non-natural or no objects present felt the exhibit taught only about the animal because "the habitat is unnatural." Second, the animal's perceived "happiness" was never affected by object type. Qualities on which the animal's happiness were based included the weather, the animal's appearance (i.e., the animal looks content, comfortable, lonely, depressed), the visitor's personal feelings (e.g., "If I had a pool on a day like today, I'd be happy," and "If I were in a cage I wouldn't be happy"), and the issue of captivity (e.g., "It's completely taken care of and has no worries," and "It doesn't belong in a zoo"). Third, perceptions of enrichment were influenced by object type in the vegetated grotto, traditional barred cage, and indoor immersion exhibit. Visitors often felt the natural objects made the animal "feel more at home" and "feel like [it was] in [its] natural environment." Non-natural objects, however, were often associated with activity. Visitors felt the objects 
were there to "play with" and "to keep the animal from getting bored" because it "doesn't have much else to do." Fourth, object type influenced the exhibit's perceived naturalism in only the barren and vegetated grottos. Though decreased naturalism was correlated with non-natural objects in the barren grotto, the items were seldom directly cited as the cause. Instead, the decreased naturalism was due to lack of plants, overabundance of stone, concrete, and rocks and lack of snow. Similarly, the increased naturalism of the vegetated grotto had little to do with the items present. This increase was due as well to the physical aspects of the exhibit, i.e., greenery, grass, and access to shade. Fifth, the perceived naturalism of the animal's behavior was only affected by object type in the indoor immersion exhibit. Above, the concept of boredom cast a negative shadow on perceptions of non-natural items. In the immersion exhibit, the opposite happened with behavior. An animal with natural objects may have "felt more at home," but that animal's behavior was considered unnatural because it had "nothing [else] to do." Conversely, non-natural objects were considered to alleviate boredom, but, in general, behaviors observed with non-natural objects seemed more natural because they were "probably...supposed to do [that]." Sixth, in none of the exhibits were perceptions of zoo animal well-being influenced by object type. In the traditional cage and immersion exhibits, however, zoo animal well-being changed as a function of the interaction between a visitor's pet ownership and object type present. Pet owners in front of the immersion exhibit with natural objects had more positive perceptions of wellbeing. This was an unexpected response because pet owners were predicted to understand enrichment's role in improving the quality of life for captive animals. Pet owners in front of the traditional enclosure, however, were more receptive to enrichment in general. More research is necessary to understand the relationship between pet ownership and zoo-related attitudes.

These data indicate that less caution and more creativity may be needed in choosing enrichment items and designing overall programs. By applying these results to daily enrichment choices, zoo managers can make more effective decisions for individual exhibits. This is one of the first published studies to address these issues [see Reade and Waran, 1996], and future research at other institutions is needed. More data will greatly enhance our understanding of visitor reactions to behavioral enrichment. In addition, there are endless questions yet to be posed. For example, would signage explaining enrichment affect perceptions? Can signage provide information appropriate for pet and non-pet owners? The more questions we continue to ask, the more appropriate our enrichment programs will be for meeting the needs of animal and visitor.

\section{CONCLUSIONS}

\section{Treatments in Which Enrichment Affected Visitor Perceptions}

1. The outdoor barren grotto was perceived as more natural when natural or no objects were present.

2. The outdoor vegetated grotto was perceived as more natural when non-natural objects were present. In the same exhibit, however, enrichment was viewed more positively when natural objects were present.

3. In the indoor immersion exhibit, general perceptions of enrichment increased with natural objects, and perceived naturalism of the animal's behavior increased with non-natural objects. 
4. In the outdoor traditional cage, the exhibit was perceived as more educational and general perceptions of enrichment increased when natural objects were present.

\section{Treatments in Which Enrichment Did Not Affect Visitor Perceptions}

1. In the outdoor barren grotto, enrichment did not affect the exhibit's perceived educational message, the animal's perceived happiness, general perceptions of enrichment, perceived naturalism of animal's behavior, or perception of zoo animal well-being. (Note: Though zoo animal well-being was influenced by a interaction between pet ownership and enrichment, zoo managers cannot control whether their visitors own pets, so it is considered a variable without an impact.)

2. In the outdoor vegetated grotto, enrichment did not affect the exhibit's perceived educational message, animal's perceived happiness, perceived naturalism of animal's behavior, or perceptions of zoo animal well-being.

3. In the indoor immersion exhibit, enrichment did not affect the exhibit's perceived educational message, animal's perceived happiness, the exhibit's perceived naturalism, or perceptions of zoo animal well-being.

4. In the outdoor traditional cage, enrichment did not affect the animal's perceived happiness, the exhibit's perceived naturalism, perceived naturalism of animal's behavior, or perceptions of zoo animal well-being.

\section{ACKNOWLEDGMENTS}

Thanks to the keepers at Brookfield Zoo who were patient and willing to juggle objects and animals for this project. In addition, Jessica Wallace was instrumental in data collection and entry, and thanks to Drs. Bobbi Low and Gary Fowler for statistical support and writing critiques.

\section{REFERENCES}

Carlstead, K.; Seidensticker J.; Baldwin, R. Environmental enrichment for zoo bears. ZOO BIOLOGY 10:3-16, 1991.

Forthman-Quick, D. An integrative approach to environmental engineering in zoos. ZOO BIOLOGY 3:65-77, 1984.

Hancocks, D. Bringing nature into the zoo: Inexpensive solutions for zoo environments. INTER NATIONAL JOURNAL FOR THE STUDY OF ANIMAL PROBLEMS 1:170-177, 1980.

Hutchins, M.; Hancocks, D.; Crockett, C. Naturalistic solutions to the behavioral problems of captive animals. Pp 198-213 AAZPA ANNUAL CONFERENCE PROCEEDINGS. Wheeling, WV: American Association of Zoological Parks and Aquariums, 1979.

Markowitz, H. Effectiveness of acoustic 'prey' Environmental enrichment for a captive African leopard (Panthera pardus). ZOO BIOLOGY 14: 371-379, 1995.

McKenzie, S.M.; Chamove, A.S.; Feistner, A.T.C Floor-coverings and hanging screens alter arboreal monkey behavior. ZOO BIOLOGY 5:339348, 1986.
Neter, J.; Kutner, M.H.; Nachtscheim, C.J.; and Wasserman, W. APPLIED LINEAR STATISTICAL MODELS, FOURTH EDITION. Chicago: Irwin, 1996.

Newberry, R. Environmental enrichment: increasing the biological relevance of captive environments. APPLIED ANIMAL BEHAVIOUR SCIENCE 44:229-243, 1995.

Reade, L.S.; Waran, N.K. The modern zoo: How do people perceive zoo animals? APPLIED ANIMAL BEHAVIOUR SCIENCE 47:109-118, 1996.

Shepherdson, D. Review of environmental enrichment in zoos: 1. RATEL 16: 35-40, 1989.

Shepherdson, D. J.; Mellen, J. D.; Hutchins, M. eds . SECOND NATURE: ENVIRONMENTAL ENRICHMENT FOR CAPTIVE ANIMALS. Washington, DC: Smithsonian Institution Press, 1998.

Tripp, J. K. Increasing activity in captive orangutans: Provision of manipulable and edible materials. ZOO BIOLOGY 4:225-234, 1985. 